\title{
Retos de la bioética frente a los nuevos escenarios del cambio climático
}

\section{Straights from bioethics in the face of the new scenarios of climate change}

\author{
Carvajal-Rodríguez, J. C; Núñez-Rodríguez, J. J; Araque-Pérez, C. E; \\ Editor Académico Alfredo Rodriguéz Escobar
}

\section{iD J. C Carvajal-Rodríguez}

departamentodeeducacion@cucuta.udes.edu.co

Universidad de Santande, Colombia

(iD J. J Núñez-Rodríguez

jo.nunez@mail.udes.edu.co

Universidad de Santander, Colombia

(iD) C. E Araque-Pérez

rectoriacuc@cucuta.udes.edu.co

Universidad de Santander, Colombia

Editor Académico Alfredo Rodriguéz Escobar

alfredo.rodriguez@ues.edu.sv

Universidad de El Salvador, El Salvador

Revista Iberoamericana de Bioeconomía y Cambio

Climático

Universidad Nacional Autónoma de Nicaragua, León, Nicaragua ISSN-e: $2410-7980$

Periodicidad: Semestral

vol. 7 , núm. 14, 2021

czuniga@ct.unanleon.edu.ni

Publicación: 21 Agosto 2021

URL: http://portal.amelica.org/ameli/

jatsRepo/394/3941761003/index.html

DOI: https://doi.org/10.5377/ribcc.v7i14.12486
Resumen: Los retos que impone el cambio climático a la bioética frente a los impactos negativos del cambio climático en la biodiversidad sugiere "Cambiar las mentalidades, no el clima”; máxima que plantea la campaña de sensibilización de la opinión pública que forma parte de la Estrategia de la UNESCO sobre el cambio climático 2018-2021, elaborada en el contexto del Acuerdo de París 2015 (COP21) y de los Objetivos de Desarrollo Sostenible (ODS) de la Agenda 2030 de las Naciones Unidas, y que la bioética debe asumir como objeto de reflexión sobre cuál debe ser el papel protagónico que deben asumir las nuevas generaciones en la conservación del planeta. Más allá de las denominaciones (eco ética, tecno ética, ética de la biotecnología, ética ambiental, geo ética o cualquier debate ético que tenga como epicentro la vida en cualquiera de sus formas, puede considerarse en pleno sentido un debate de naturaleza bioética, cuyo propósito será la de preservar y promover la vida de las generaciones presentes y futuras y de la naturaleza con sentido de la justicia. En este orden de ideas la necesidad de un cambio será fundamental para la conservación de la especie y es aquí donde vemos un panorama esperanzador en la Bioeconomia, como disciplina que puede aportar a éste propósito. La bioética debe entrar como disciplina e hija menor de la ética a construir un discurso que se articule con otras disciplinas en la defensa de lo biodiverso, tarea que tenemos como propósito en este escrito.

Palabras clave: Bioética, Medio ambiente, Cambio climático, Bioeconomia.

Abstract: The challenges that climate change imposes on bioethics in the face of the negative impacts of climate change on biodiversity suggests "Change mentalities, not the climate"; maxim raised by the public awareness campaign that is part of UNESCO's Strategy on Climate Change 2018-2021, drawn up in the context of the 2015 Paris Agreement (COP21) and the Sustainable Development Goals (SDG) of the United Nations 2030 Agenda, and that bioethics should take on as an object of reflection on what should be the leading role that new generations should assume in the conservation of the planet. Beyond the denominations (Eco ethics, techno ethics, ethics of biotechnology, environmental ethics, geo ethics or any ethical debate that has life as its epicenter in any of its forms, a debate of a bioethical nature can be considered in the full sense, the purpose of which will be the to preserve and promote the life 


\begin{abstract}
of present and future generations and of nature with a sense of justice. In this vein, the need for a change will be fundamental for the conservation of the species and this is where we see a hopeful outlook in the Bioeconomy, as a discipline that can contribute to this purpose. Bioethics must enter as a discipline and youngest daughter of ethics to build a discourse that is articulated with other disciplines in the defense of the biodiverse, a task that we have as our purpose in this writing.
\end{abstract}

Keywords: Bioethics, Environment, Climate change, Bioeconomy.

\section{LA NATURALEZA COMO UNA TOTALIDAD.}

Los nuevos escenarios del cambio climático plantean a la bioética una reflexión epistemología en el marco de lo filosófico histórico, en el que emerjan nuevas categorías que alimenten la construcción de un discurso persuasivo orientado a la armonización con la naturaleza como totalidad ontológica. Para Aristóteles (1995), "Algunas cosas son por naturaleza, otras por causas. Por naturaleza los animales y sus partes, las plantas y los cuerpos simples como la tierra, el fuego, el aire y el agua, pues decimos que éstas y otras cosas semejantes son por naturaleza. Todas estas cosas parecen diferenciarse de las que no están constituidas por naturaleza, porque cada una de ellas tiene en sí misma un principio de movimiento y de reposo, sea con respecto al lugar o al aumento o a la disminución o a la alteración. Por el contrario, una cama, una prenda de vestir o cualquier otra cosa de naturaleza semejante, y en tanto que son productos del arte, no tienen en sí mismas ninguna tendencia natural al cambio; pero en cuanto que, accidentalmente, están hechas de piedra o de tierra o de una mezcla de ellas, y sólo bajo este respecto, la tienen. Porque la naturaleza es un principio y causa del movimiento o del reposo en la cosa a la que pertenece primariamente y por sí misma, no por accidente" Aristóteles (1994)

La naturaleza vista aquí como el conjunto de todo lo que forma el universo en cuya creación no ha intervenido el hombre y que no podemos perder de vista nuestro planeta como un corpus en el que todas sus partes son una unidad y que cualquier alteración es un intento de desintegración, lo que sugiere una apuesta por la conservación y cuidado tarea que debe asumir una bioética entendida como disciplina reflexiva y critica sobre las acciones humanas cuyo paradigma debe ser el concepto de sustentabilidad como medio para lograr el equilibrio y la supervivencia Plachciak (2010); en éste sentido la bioética se hace necesaria en el propósito de asumir retos como lo plantean Carlotto, Pereira y Dinis (2021): la bioética ambiental tiene como tarea la promoción de la salud humana de manera concurrente con la preservación del medio ambiente, que junto con la educación superior (ES) tiene la tarea de lograr competencias enfocadas en el desarrollo sustentable (DS), la responsabilidad social (RS) y el mantenimiento de principios bioéticos y ambientales. En esta dirección la bioética ambiental debe asumir de otras disciplinas postulados que coadyuden a la reflexión crítica sobre la conservación del medio ambiente biodiverso, asumiendo los anteriores postulados en la creación de un nuevo orden de valores cono ya Ray y Anderson (2000), lo visualiza; el surgimiento de un nuevo tipo de valores entre los individuos que tienden a ser más responsables con el medio ambiente y adopten los principios y valores posmodernos que guíen su actuar en direcciones opuestas de las sociedades modernas. Estos individuos o "creativos culturales" contraponen valores más ligados al respeto del medio ambiente; para (Cortina, 2016), la bioética del siglo XXI se ve enfrentada al reto de colaborar en la construcción de un mundo justo y sostenible. Para Habermas, (1995) el mundo de hoy está ávido de tolerancia y respeto por la diversidad; palabras que encarna el espíritu alemán en los posmodernos de la escuela de Frankfurt, y que Apel (1985), bajo un argumento deontológico-discursivo, plantea la necesidad de integrar los intereses de todos los afectados, en donde se integren bajo la premisa de la tolerancia la posibilidad de espacios a las diferentes formas de vida socio-cultural y biodiversa. Para Ibarra, J., Velarde, M. (2017), este término ligado a ideas de justicia, 
equidad social y económica, así como un respeto inefable hacia el medio ambiente natural que no surgió abruptamente, sino que fue resultado de una condición del pensamiento humano que se ha identificado como posmoderna. (Error 1: Ibarra, J., Velarde, M. (2017 is linked to an element that doesn't exist)

En este sentido la categoría de respeto está inmersa en la categoría anterior, la idea de una ética universal sustenta la idea de que el mundo posmoderno tiene unos problemas comunes y universales que deben ser resueltos desde una ética discursiva que pueda lograr espacios de consensos no coactivos en donde la acción comunicativa sea libre y aporte a la defensa de nuestro planeta, tarea que nos compete a todos. En este marco de reflexión la bioética como disciplina que se nutre de esta ética discursiva debe asumir la responsabilidad con el medio ambiente, que ya no es un imperativo individual sino colectivo Roque (2016).

\section{Ruptura HOMBRE NATURALEZA}

Otro de los compromisos de la bioética en lograr armonizar al hombre con la naturaleza, papel que en el pasado cumplían a cabalidad los mitos, pero en especial los ritos como ejercicio de reconocimiento y respeto con la naturaleza y su biodiversidad, tarea propuesta por Morris (1987), que primariamente debe ser enfocada a la transformación de la mente humana más que a la naturaleza social y económica que anteriormente se creía eran las raíces de la crisis o, como él llama del dilema; crisis iniciada con la pérdida de significado en sus sentidos filosófico o religioso. La bioética aquí debe enfilar su "artillería" sobre la tarea reflexiva y pedagógica, orientada a la transformación del pensamiento humano y no de la naturaleza, reto en las que las instituciones educativas deben ser protagonistas.

Si hacemos una línea del tiempo podemos constatar que hasta la época moderna la totalidad de la naturaleza, de los fenómenos, la visión del mundo en general era la de un mundo encantado que implicaba una conciencia participativa o de identificación con el ambiente. Con el advenimiento de la modernidad se da un continuo desencantamiento, una separación y distanciamiento total de la naturaleza; el desencantamiento del mundo es intrínseco a la visión científica del mundo que produjo la época moderna; pero esto tuvo como consecuencia la inestabilidad de sostenerse a sí misma; la modernidad cuestionó unos valores ya creados, pero no creó sus sustitutos y dejó al hombre en el abismo. La humanidad en el mayor por ciento de su historia vivió encantada, participando de su mundo y concibiéndose como parte integral de él; la época moderna sacó al hombre de su encanto. La modernidad considera que las épocas anteriores a ella han estado constituidas por visiones del mundo desviadas y que solamente ella es la que ha dado con el surgimiento de la ciencia, una verdadera visión libre de presuposiciones animísticas o metafísicas, de superstición y pensamiento confuso, proceso que en Occidente fue impulsado dos mil años antes de Jesucristo con la cultura griega y ejecutada en absoluto en la época moderna, el mundo es desencantado progresivamente, desendiosado, en el que fue gradualmente desapareciendo la conciencia participativa y el animismo Blackmore, I., Iannotti, L., Rivera, C., Waters, W.F., Lesorogol, C. (2021). .

El mundo griego, con Homero y con la intervención de Platón, comenzó a considerarse como una personalidad autónoma apartada de sus actos, una conciencia separada (distinción sujeto/objeto), en el que la razón se convierte en la esencia de la personalidad y se caracteriza por el distanciamiento de uno mismo de los fenómenos, manteniendo la propia identidad.

Para Junges (2016), la tarea de una bioética ambiental sería asumir la perspectiva de la hermenéutica que cuestiona supuestos, teorías y prácticas, consideradas científicas, naturalizadas como sentido común, sin ningún espíritu crítico, permitiendo abrir horizontes de perspectivas nuevas. Para Santos (1989), aquí, hermenéutica significa "asumir la tarea de deshacer el estado de interpretación heredado y dominante, de revelar motivos ocultos, de descubrir tendencias y rutas de interpretación no siempre explicitadas y de volver a fuentes originales que motivan toda explicación a través de una estrategia de desmontaje”. En esta línea Heidegger $(2002,51)$, plantea que las discusiones suscitadas por una bioética hermenéutica, en clave egocéntrica, que pueden provocar un choque crítico que cuestione el sentido común naturalizado, 
despertando a una sensibilidad ecológica y conciencia ética de las consecuencias del binomio tecnología y vida en la economía y la agricultura.

En este punto, es importante llegar a una definición adecuada de la crisis ambiental que sea coherente con la lógica de la sostenibilidad ambiental, es decir, una comprensión de la crisis que tenga como referencia las interrelaciones e interdependencias ambientales. En este sentido, se puede decir que la crisis ecológica es el resultado del drástico desajuste entre los procesos cíclicos, conservadores y autorrecurrentes de la biosfera y los procesos lineales e innovadores que buscan maximizar los beneficios humanos de la tecnosfera en la región. En otras palabras, la lógica de las interdependencias ambientales de la reproducción de la vida está en completa contradicción con la lógica fragmentaria e independiente del funcionamiento de la técnica. La contradicción entre las dos lógicas hace que el medio ambiente sea insostenible, con repercusiones para la supervivencia de muchos seres vivos y humanos, en donde la bioética puede jugar un papel importante en este despertar a la conciencia de los efectos del binomio tecnología y vida e o en palabras de Rheeder (2021), una creación dañada daña la salud del ser humano y, por tanto, la protección de la naturaleza es una obligación indiscutible. En este sentido Kozlovsky (1974) afirma que los esfuerzos para rectificar nuestros problemas ambientales son meros sustitutos, sustituibles, a menos que cambien nuestros puntos de vista sobre lo que somos nosotros mismos y la realidad de nuestra existencia, basada en la naturaleza o como lo plantea Pérez (2000) el desarrollo de una Bioética del Medio Ambiente, un planteo ético de la calidad de vida en el planeta, una ética y un patriotismo planetario que coloque a la nave tierra en el rumbo correcto, lo que hace imperioso entonces cambiar el clásico concepto de hombre contra la naturaleza, por hombre en o con la naturaleza, forma nueva de consideración de la sociedad humana.

La Importancia y compromisos de protección del medio ambiente, ahora y como un deber hacia la humanidad que está por venir, pertenece a los orígenes del discurso bioético, y se enriquece con el aporte que proviene de la teoría intergeneracional del derecho y la Constitución, para D'Aloia, A. (2019), la atención al futuro (en términos de responsabilidades y deberes hacia las generaciones futuras o incluso de los propios derechos) es uno de los temas más fascinantes y complicados del constitucionalismo moderno, y un verdadero desafío para las categorías tradicionales de política y democracia, reto que tiene las sociedades posmodernas en los compromisos por salvar nuestro hogar común.

\section{LA VISIÓN SIMBÓLICA DEL MUNDO COMO IMPERATIVO ESPERANZADOR.}

Con los nuevos escenarios que nos plantea el cambio climático la bioética como reflexión tiene la responsabilidad de entablar un dialogo con otras disciplinas que le permitan ir afianzándose como una autoridad epistémica. Aquí retomaremos algunos conceptos que deben recuperarse en ese propósito como la idea de incorporar las teogonías de los aborígenes que como bien lo decía en una entrevista Chomsky (2017), son los que "Mediante planes de manejo de sus recursos naturales, conocimientos ancestrales, y sobre todo a través de la defensa de su territorio frente a empresas extranjeras que extraen y vacían sus suelos de los recursos naturales latinoamericanos: minerales, aceite de palma, agua, tierras”. En esta misma dirección podemos citar lo ocurrido en abril de 2019, con el pueblo Waorani en la Amazonía de Ecuador que ganó una batalla legal clave contra los planes de vender concesiones petroleras en su territorio indígena, como lo resalta Alto (2020), la violación de un entorno natural, sino las amenazas a las cualidades de la tierra waorani (wao öme) que permiten que las personas y otros seres "vivan bien". Ese vivir bien aquí representa una alternativa de desarrollo en el que se pueda fortalecer la simbiosis hombre naturaleza, en el que se pueda articular nuevos proyectos innovadores como lo plantea Scheyvens, Carr, Movono, Higgins y Mika (2021) a través de estudios de casos de turismo indígena entre pequeñas y medianas empresas en Fiji, Australia y Aotearoa Nueva Zelanda y como estas empresas de turismo indígena operaban en el espíritu de muchos de los ODS, incluso cuando tenían poca conciencia de estos objetivos. También encuentra que los valores y formas de vida indígenas, como la apreciación de la conexión intrínseca entre naturaleza y cultura: se corresponden 
con la agenda de los ODS y podrían utilizarse para avanzar aún más en esta agenda de manera que beneficien a los pueblos indígenas y no indígenas. Estos nuevos emprendimientos representarían una buena alternativa de conexión con lo cultural ancestral favoreciendo las economías culturales.

Otra idea que tiene que ser retomada por el discurso bioético el concepto del hombre antiguo religioso, para el cual todo el universo era sagrado, en el cual experimentaba algunas hierofonías; para Eliade (1967: 19): "lo sagrado puede manifestarse en las piedras o en los árboles; nuestro mundo es una tierra santa porque es un lugar más próximo al cielo, el mundo se deja captar en tanto que mundo, en tanto que cosmos en la medida que se revela cómo mundo sagrado". En este sentido tendríamos que volver a recuperar desde una nueva visión de la bioética el valor religioso del hombre primitivo que concibe a la naturaleza siempre cargada con un gran valor: "el cosmos vive y habla". Ese valor espiritual que se fortalece en lo ritual como ese dialogo con la "Pacha Mama”, en donde los ritos de tránsito juegan un papel importante en la vida del hombre religioso, puesto que son la expresión de esa unión recíproca entre hombre-naturaleza, ritos que a mi manera de ver la bioética debe incorporar en su constructo teórico como un elemento articulador del hombre posmoderno con la naturaleza biodiversa en su tarea de buscar nuevamente reconciliar hombre su entorno natural lo que haría posible la salvación no solo del hombre sino del planeta.

Esa relación simbólica y sacralizada del mundo, que hace referencia a un orden cósmico, una gran cadena, en la que cada ser ocupa el lugar que le corresponde. En ello, el hombre ocupa un lugar intermedio: participa del mundo inteligible y del terrenal, es mediador entre el mundo natural y el divino. Es el mismo espíritu de la naturaleza el que hace pensar un mundo simbólico y sacralizado, es ella quien exige los ritos y mitos que se ha creado el hombre, ella reclama que le reconozcan como lugar sagrado y que dejen seguir su ritmo natural.

Para los hombres antiguos el mundo era un todo organizado, la naturaleza como un libro que posee un conjunto de signos con significación precisa, o en palabras de Francis Bacon el hombre debe ser el ministro e intérprete de la naturaleza. En la misma dirección o con rasgos de la edad antigua, el mundo, al igual que el hombre, son creados por un mismo creador y la naturaleza y su belleza habla de él. "En tal mundo, todo tenía un sentido simbólico. Así era para los actos de la vida cotidiana: trabajo, comida, etc." Santuc (2005), rito y mito son pues, formas de establecer un diálogo respetuoso y fecundo con la naturaleza, simbiosis presente en todas las culturas de la tierra y sobre todos en los antiguos en donde existía una conexión mítico religiosa sobre todo ese concepto de Madre Tierra o, con el término de los antiguos griegos, Gaia*como lo plantea Lovelock (1983) y que ha tenido enorme importancia a lo largo de toda la historia de la humanidad.

La bioética como disciplina debe retomar a las teogonías aborígenes y asumir de ellas esos elementos reconciliatorios con la Pachamama ("la Madre Tierra") propios del mundo andino que no es otra que la expresión de la búsqueda de una "alianza" duradera con las fuerzas naturales. Esta divinización en la que interviene un vínculo de amor. La madre tierra no es solo una unión de fuerzas que no se pueden controlar, sino que es un ser capaz de una afectividad profunda en relación al hombre en la que se debe crear esos lazos que fortalezcan esas nuevas visiones y relaciones con el mundo natural hoy cuando el futuro planetario está en manos de todos y es una responsabilidad frente a los nuevos retos que nos impone la variedad climática, impactos que se pueden evidenciar en el agotamiento de la tierra y los recursos impactando las poblaciones humanas en especial a la población rural como lo plantean Blackmore, Iannotti, Rivera, Waters y Lesorogol (2021), "la degradación del suelo relacionada con el uso excesivo de la tierra y la erosión han provocado una disminución de la producción agrícola y dificultades económicas. Esta dinámica desafiante ha llevado a muchos miembros de la comunidad a migrar a las ciudades en busca de trabajo y ha tenido un impacto negativo en la salud de los niños pequeños y sus madres”. Para Gordeeva (2021), la degradación y pérdida de los bosques es uno de los factores que contribuyen a alterar el equilibrio de la naturaleza y aumentar el riesgo y la exposición de las personas a las enfermedades zoonóticas, dejando al desnudo la falta de compromiso y buena gobernanza tanto a nivel internacional como nacional en temas ambientales. 


\section{Conclusiones}

A manera de conclusión creo pertinente resaltar que la importancia de la bioética como una disciplina que debe orientar su interés en orientar las nuevas conductas en las que deje de ver la naturaleza como un recurso, cuya apreciación se basa en razones utilitarias, emanadas del sistema económico, en los que los medios de producción, los intereses de los mercados globales, el consumo indiscriminado de los recursos naturales no renovables sumado a los impactos negativos del cambio climático y la utilización indebida de los adelantos de la ciencia y la tecnología han ocasionado los principales problemas ecológicos de la contemporaneidad. La vida del planeta se va directamente afectada con: la deforestación de los bosques y selvas, el recalentamiento climático, la emisión de gases tóxicos, la contaminación de las fuentes hídricas, la contaminación de los residuos en las ciudades y la polución acústica Rey (2019).

Frente a éste panorama desesperanzador surge el discurso de la bioeconomia como alternancia epistémica y da una luz hacia la reconciliación hombre naturaleza, que en los cincuenta presenta un cambio de paradigma para la economía: la bioeconomia o la economía ecológica Georgescu-Roegen (2003). Aquí la bioeconomía, establecida como la relación entre economía y ecología, es un nuevo enfoque que resalta la importancia de los recursos de origen biológico y la relación con los procesos económicos; esta relación plantea problemas por la cantidad limitada de los recursos accesibles que existen, los cuales están distribuidos de forma desigual Georgescu-Roegen (1977). Dentro de éste nuevo paradigma aparecen nuevos emprendimientos emergentes que en el caso de Colombia se visualizan en las zonas de conflicto, en donde muchos actores se han reincorporado a la vida civil y laboral a través de ellos. Un caso concreto son como lo plantean Lora-Ochoa, Pinedo-López, Burgos-Salvador (2018), como Las cooperativas rurales, además de lograr la inserción de los desmovilizados a la vida productiva, contribuyen también con la reconstrucción del tejido social en el campo, principalmente en las zonas más afectadas por la violencia y por los bajos niveles de desarrollo económico, lo cual fomenta, a su vez, el capital social y el aprovechamiento de los talentos y la creatividad de las personas que no han podido explotar todo su potencial.

En este sentido la bioeconomía sería una buena compañera de la bioética en su propósito de generar responsabilidad en la tarea de conservar la naturaleza para las generaciones actuales y las futuras Jonas (1995); retos que nos impone la posmodernidad a todos como imperativo bioético: la conservación y la protección a partir de un sistema de conversión respetuoso, los recursos naturales, estos últimos por ser finitos y esenciales para la existencia de todos los seres vivos Scheyvens, R. , Carr, A. , Movono, A., Higgins-Desbiolles, F. , Mika, JP. (2021), Berman, M. (1987).

\section{REFERENCIAS CITADAS}

Alto, C. (2020). "¡Nuestra tierra no está a la venta!" Impugnando el petróleo y traduciendo la política ambiental en el Ecuador amazónico". Revista de Antropología Latinoamericana y Caribeña 25 (2), págs.301-323

Aristóteles. (1994). Metafísica, I. Gredos: Madrid.

Aristóteles. (1995). Física I. II, Gredos: Madrid: 128-129.

Apel K-O. (1985). La transformación de la filosofía. Madrid: Taurus, p. 17.

Carlotto, I.N., Pereira, R.C.S., Dinis, M.A.P. (2021). Environmental Bioethics, Sustainable Development and Social Responsibility in Higher Education World Sustainability Series, pp. 551-563. 1). Disponible en: https:// www.scopus.com/inward/record.uri?eid=2-s2.0-85103984404\&doi=10.1007\%2f978-3-030-59975-

Berman, M. (1987). El Reencantamiento del Mundo, Cuatro Vientos, Santiago de Chile, pp. 15-130.

Blackmore, I., Iannotti, L., Rivera, C., Waters, W.F., Lesorogol, C. (2021). Land degradation and the link to increased livelihood vulnerabilities among indigenous populations in the Andes of Ecuador Land Use Policy, 107, art. no. 105522. Disponible en: https://www.scopus.com/inward/record.uri?eid=2-s2.0- 
Cortina, A. (2016). Bioética para el siglo XXI: construyendo esperanza. Revista Iberoamericana De Bioética, (1), 1-12. Disponible en: https://revistas.comillas.edu/index.php/bioetica-revista-iberoamericana/article/ view/6764/6561

Chomsky, N. (2017). Los pueblos indígenas están salvando al planeta de un desastre ambiental". Disponible en: https://ecoosfera.com/2017/03/noam-chomsky-activismo-ambiental-indigena-latinoamericano-video/

D'Aloia, A. (2019). Bioética ambiental, sustentabilidad, teoría intergeneracional de la constitución. Revista BioLaw, (Edición especial 2) , págs. 645-678

Eliade, M. (1981). Lo Sagrado y lo Profano. Guadarrama / Punto Omega 4ta. Edición. Traducción: Luis Gil.

Georgescu-Roegen, N. (2003). Bioeconomia. Italia: Bollati Borinchieri.

Georgescu-Roegen, N. (1977). Inequality, limits and growth from a bioeconomic viewpoint review of social economy. Perspectives on the Nature of Social Economics, 35(3), 361-375.

Gordeeva EM Evolución del Reglamento Forestal Internacional. Revisión de la ley de Kutafin . 2021; 8 (2): 155-198. https://doi.org/10.17803/2313-5395.2021.2.16.155-198

Habermas J. (1985). Conciencia moral y acción comunicativa. Barcelona: Península.

Heidegger, M. (2002). Interpretaciones fenomenológicas sobre Aristóteles. Indicación de la situación hermenéu-tica [Informe Natorp]. Madrid: Ed. Trotta.

Ibarra, J., Velarde, M. (2017). La Posmodernidad y Su Influencia En La Sustentabilidad

Jonas, H. (1995). El principio de responsabilidad: ensayo de una ética para la civilización tecnológica. Barcelona: Herder.

Koslovsky, D. (1974). An ecological an evolucionary ethic.Englewood Cliffs, Prentice Hall, page 101.

Lora, C., Pinedo, J. y Burgos, M. (2018). Cooperativas en el sector rural para la reintegración productiva de los desmovilizados. Cooperativismo \& Desarrollo, 26(112). https://doi.org/10.16925/co.v25i112.2035

Lovelock, J. E. (1979). Gaia, una nueva visión de la vida sobre la tierra. Barcelona, Ediciones Orbis, S.A. Disponible en: http://mateandoconlaciencia.zonalibre.org/gaia.pdf

Pérez, A. (2000). Bioética y Medio Ambiente. El gran desafío del siglo XXI. Argentina, Cuadernos de Bioética, Programa de Bioética (PROBE).

Plachciak, A. (2010). Sustainable Development in Postmodern Society. Economics \& Sociology, No 2, pp. 86-91 https://doi.org/10.14254/2071-789X.2010/3-2/9

Ray, P. y Anderson, S. (2000). The cultural creatives. New York. Harmony Books.

Rheeder, A. (2021). La protección del medio ambiente como principio bioético mundial: la tradición de la fe protestante en conversación con la organización de las naciones unidas para la educación, la ciencia y la cultura. Verbum et Ecclesia 42 (1) , a2186

Rey Lema, D. M. (2019). Bioética y bioeconomía: disciplinas para supervivencia del mundo planetario. Trilogía Ciencia Tecnología Sociedad, 11(20), 177-204. Disponible en: https://revistas.itm.edu.co/index.php/trilogia/ article/view/1217

Roque, J. (2016). Principios ecológico-éticos de la sostenibilidad socio ambiental: el caso de la Economía y de la Agricultura. Revista Iberoamericana De Bioética, (1), 1-13.

Santos, B. S. (1989). Introdução à uma Ciência Pós-Moderna. Rio de Janeiro: Ed. Graal.

Santuc, V. (2005). El topo en su Laberinto, Lima: Universidad Antonio Ruíz de Montoya.

Scheyvens, R., Carr, A. , Movono, A. , Higgins-Desbiolles, F. , Mika, JP. (2021). El turismo indígena y los objetivos de desarrollo sostenible. Annals of Tourism Research 90, 103260

Scheyvens, R. , Carr, A. , Movono, A. , Higgins-Desbiolles, F. , Mika, JP. (2021). El turismo indígena y los objetivos de desarrollo sostenible. Annals of Tourism Research 90,103260 https://doi.org/10.1016/j.annals.2021.103260

Morris, Douglas W. "Ecological scale and habitat use." Ecology 68.2 (1987): 362-369.

Junges, José Roque. "Hermenéutica como profanación de los nuevos sagrados: desafío y tarea para la bioética." Revista Bioética 24 (2016): 22-28. 